\title{
Editorial
}

\section{An Acknowledgement to the HCA Healthcare Journal of Medicine's Reviewers and Editors for the 2 nd Half of 2021}

Bruce Deighton, PhD'; Hossein Akhondi, MD, FACP ${ }^{1,2}$; D. Scott Lind, MD ${ }^{1,3}$; Graig Donini ${ }^{1}$

\section{Abstract}

Author affiliations are listed at the end of this article.

Correspondence to: Graig Donini

HCA Healthcare Graduate

Medical Education

2000 Health Park Drive

Brentwood, TN 37027

(Graig.Donini@

HCAhealthcare.com)

thank those behind the scenes who make this publication possible. Our journal would not be possible without the assistance of our reviewers, authors, and board members.

\section{Keywords}

scholarly communication; peer review, research; open access publishing; education, medical, graduate; medical journalism

The HCA Healthcare Journal of Medicine again thanks the reviewers and editorial staff who have helped over the second half of 2021. This past year has proven to be as challenging, if not more exhausting, to our colleagues in medicine than 2020.

In the first part of this new year, the journal continued to improve the quality of our publication and attract new authors and readers. Moving forward, we plan to update our author guidelines to increase our adherence to the best practices in scholarly publishing. This update will include new checklists for our various article types and increased scrutiny from our editors and reviewers on maintaining these new standards. The journal will also shift from a modified AMA format to one that follows the AMA publishing guidelines as closely as possible.

To expand our audience, the journal has launched a Twitter feed to share the journal's activities with the broader medical community. You can find and follow us @hcajom1. The journal has also launched an interview series. These author interviews provide additional insight into the works they have published with

us. They can be found at: https://scholarlycommons.hcahealthcare.com/hca jom interviews/

As always, we encourage our readers to submit their work to the journal, both scientific and personal, and ask them to consider sharing their expertise as peer reviewers. Authorship and peer review with the journal are forms of scholarly activity recognized by the ACGME.

Thank you for your continued support of the HCA Healthcare Journal of Medicine.

\section{Reviewers}

Ahmad Abazid

Khalid Abusaada

Hossein Akhondi

Afsaneh Alavi

Jeffrey Anderson

Debra Angelo

Paul Banerjee

Rachael Barnes

Heather Barnett

Elisabeth Barrar

J. David Baxter

Haryashpal Bhullar

Vedavyasa Biliyar

\section{HCA is Healthcare}

\section{www.hcahealthcarejournal.com}

(C) 2022 HCA Physician Services, Inc. d/b/a Emerald Medical Education
HCA Healthcare Journal of Medicine 
Hillary B. Boswell

Jennifer Broyles

Ning Cao

Luigi Cardella

Carley Castelein

Clay Cockerell

Armanda Cognetta

Nicholas Connors

Ettore Crimi

Nemer Dabage

Tom Davis

Julie DeCesare

Adeline Deladisma

Oliwier Dziadkowiec

Sulaiman Farooqui

Julia Fashner

Nickie D. Greer

Susan Griffee

Scott Gutovitz

Jacqueline Halladay

Chris Hawk

Rachel Hogan

Afra Janarious

Shane P. Jenks

Brent Kaplan

Saby Karuppiah

Gerald Keller

Jessica Kraker

Avi Landman

Abraham Joseph Layon

Richard P. Leggett

David Scott Lind

Amy Lu

Abhishek Lunagariya

Alexandra Marcelli

Josephin Mathai

Melissa Mendez

Orlando Morejon

Ramesh Nathan

Mary O'Dowd

Michelle Ozcan

Maulik Patel

Tom Peters

Anush S. Pillai

Norman Pillsbury

Aaron Poole

David M. Quillen

Afsha Rais

Fergie Ramos

Vaibhav Rastogi

Stephen Richardson

Yolonda Sanders

Andras Schaffer

Michael J. Schurr
Anthony Shadiack

Pinak A. Shah

Anand Subramanian

Richard Sundermeyer III

Adrian A. Valdivia

Craig Van Dien

Clara L. Alvarez Villalba

Mario Villafani

Editorial Board

L. Hayley Burgess

Steve Carpenter

Robert Chait

Brady DeHart

Mary Downing

Barbara Gracious

Jacqueline Halladay

Julie Jacko

Rahul Kashyap

Sewon Lee

Abhishek Lunagariya

Sherri Morgan

Vishwanath Pattan

Anthony Pearson-Shaver

Resident and Fellow Board Members

Patrick Melmer

Carlos Vargas

Clinical Co-Editors

Hossein Akhondi

D. Scott Lind

Editor-in-Chief

Bruce Deighton

Journal Production

Production Editors

Heather Fach

Jan Haley

Mary Alice Keller

Lindsay Million

Lindsay Pate

Ashton Stahl

\section{Marketing and Communications}

Tyler Browning

\section{Managing Editor}

Graig Donini 


\section{Conflicts of Interest}

Dr Lind declares compensation for licensing a simulation technology.

Drs Deighton and Akhondi and Mr Donini declare they have no conflicts of interest.

Dr Deighton and Mr Donini are employees of HCA Healthcare Graduate Medical Education, an organization affiliated with the journal's publisher.

Dr Akhondi is an employee of West Florida Hospital, a hospital affiliated with the journal's publisher.

Dr Lind is an employee of Orange Park Medical Center, a hospital affiliated with the journal's publisher.

This research was supported (in whole or in part) by HCA Healthcare and/or an HCA Healthcare affiliated entity. The views expressed in this publication represent those of the author(s) and do not necessarily represent the official views of HCA Healthcare or any of its affiliated entities.

\section{Author Affiliations}

1. HCA Healthcare Graduate Medical Education

2. West Florida Hospital, Pensacola, FL

3. Orange Park Medical Center, Orange Park, $\mathrm{FL}$ 